http://jmscr.igmpublication.org/home/ ISSN (e)-2347-176x ISSN (p) 2455-0450

crossref DOI: https://dx.doi.org/10.18535/jmscr/v7i12.59

Journal Of Medical Science And Clinical Research

\title{
Randomized comparative study between ProSeal laryngeal mask airway (PLMA) and Endotracheal tube (ETT) for airway management in laparoscopic cholecystectomy under general anesthesia
}

\section{Authors}

\author{
Dr Shyamli Jamwal ${ }^{1}$, Dr Vatika Bhardwaj ${ }^{2 *}$, Dr Vishawjeet Singh ${ }^{3}$, Dr Rajneet Kaur \\ ${ }^{1}$ Assistant Professor, Department of Anaesthesia, Sri Lal Bahadur Shastri Government Medical College \\ Mandi, Himachal Pradesh, India \\ ${ }^{2}$ Senior Resident, Department of Anaesthesia, Sri Lal Bahadur Shastri Government Medical College Mandi, \\ Himachal Pradesh, India \\ ${ }^{3}$ Assistant professor, Department of Anaesthesia, Sri Lal Bahadur Shastri Government Medical College \\ Mandi, Himachal Pradesh, India \\ ${ }^{4}$ Associate Professor, Department of Anaesthesia, PanditJawaharlal Nehru Government Medical college \\ Chamba, Himachal Pradesh, India \\ *Corresponding Author \\ Dr Vatika Bhardwaj
}

Senior Resident, Department of Anaesthesia, Sri Lal Bahadur Shastri Government Medical College Mandi, Himachal Pradesh, India

\footnotetext{
Abstract

Background: The anesthetic technique employed in laparoscopic procedures offers many challenges and is limited most frequently to general anesthesia with controlled ventilation. Till date cuffed endotracheal tube is being considered ideal for such procedures but lesser invasive devices like PLMA are being successfully used nowadays.

Aims: The present study was conducted to compare PLMA and ETT for airway management in laparoscopy cholecystectomy under general anesthesia.

Material and Methods: The clinical trial included 50 patients scheduled for elective laparoscopy cholecystectomy. The ethical committee clearance and written consent were taken and patients were randomly allocated to either PLMA or ETT group. Insertion characteristics of PLMA and ETT and of nasogastric tube (NGT) via PLMA and ETT were noted. Hemodynamic responses, intra-operative as well as postoperative complications were also compared in both the groups.

Results: There was no demographic difference. The difference in insertion attempts as well as the time taken for insertion was significantly less in PLMA group than ETT group. We observed that HR,SBP, $D B P, M A P$ values were comparable at all intervals except for those after insertion. There was no case of regurgitation or aspiration noted in any of the patients in each group. Post-operative complications were mainly seen in ETT group with no statistical difference.

Conclusion: PLMA and ETT show similar efficacy during laparoscopy cholecystectomy under general anesthesia and so PLMA is an efficient and safe tool for airway management.

Keywords: ProSeal, Laparoscopic cholecystectomy, alternative to endotracheal tube.
} 


\section{Introduction}

The modern age of laparoscopic surgery was ushered in with the incorporation of a miniature video camera attached to the eyepiece of a laparoscope allowing multiple assistants to view the operative field from the same vantage point. With the introduction of minimally invasive laparoscopic surgery tissue trauma is significantly less than that with conventional open procedures offering the advantages of reduced post-operative pain, shorter hospital stay, more rapid return to normal activities and significant cost savings.

The physiological effects of intraperitoneal $\mathrm{CO}_{2}$ insufflation combined with variations in patient positioning can have a major impact on cardio respiratory function. Intra-operative complications associated with blind trocar insertion, gas embolism, pneumothorax \& surgical emphysema along with the difficulty in evaluating the amount of blood loss make laparoscopy a potentially high risk procedure.

The anaesthetic technique employed offers many challenges and is limited most frequently to general anesthesia with controlled ventilation to reduce the increase in $\mathrm{PaCO}_{2}$ and to avoid ventilatory compromise due to pneumoperitoneum $\&$ initial trendelenburg position.

For some anesthesiologists, the combination of positive pressure ventilation with CLMA (classic laryngeal mask airway) evokes fear of gastric distension, pulmonary aspiration of gastric contents and inadequate ventilation especially in laparoscopic procedures. Till date the cuffed tracheal tube is considered as gold standard for providing a safe glottic seal for such procedure. The LMA offers a spectrum of advantages over tracheal tube starting from no need for instrumentation and laryngoscope, less trauma to tissues $^{1}$, less incidence of sore throat ${ }^{2}$ and bacteremia ${ }^{3}$ causing less morbidity to the patient in post-operative period.

As the time went on Proseal Laryngeal Mask Airway -PLMA (Laryngeal Mask Company, Henley on Thames, UK), was designed to overcome much of the drawbacks of CLMA associated with positive pressure ventilation. PLMA is a double- lumen, double- cuff LMA i.e. an additional drain tube running parallel to a reinforced airway tube. This permits access to gastrointestinal tract and aids nasogastric tube (NTG) insertion which isolates alimentary tract from respiratory tract $\&$ hence provides additional protection against regurgitation ${ }^{4}$. The double cuff provides a better seal around the glottis at lower mucosal pressures, thus providing an option of administering intermittent positive pressure ventilation. The built-in bite-block reduces the chances of damage to the device by inadvertent biting by the teeth of the patient and danger of obstruction.

So PLMA is being increasingly considered as an alternative airway device for a wide range of laparoscopic surgical procedures including laparascopic cholecystectomy ${ }^{5,6}$. The aim of our study is to compare the efficacy and safety of PLMA with ETT in patients undergoing laparoscopic surgeries under general anesthesia.

\section{Material \& Methods}

Study Design: A prospective, double-blind, randomized clinical trial was performed. The patients were randomly divided into two groups (according to a computer generated plan) - the ProSeal group as Group $\mathrm{I}(\mathrm{n}=25)$ and the ETT group as Group II $(\mathrm{n}=25)$.

\section{Patient Selection}

After obtaining approval from Ethical Committee of the institution, informed written consent was taken from fifty patients who were chosen to undergo elective laparoscopic surgeries under general anesthesia. The duration of this study was 1 year. Patients of either gender with ASA-Grade I weighing between $30-70 \mathrm{~kg}$ within age group of 20-60 years was included.

Patients excluded were - those likely to pose problems in airway establishment (limited mouth opening, anticipated/known difficult airway, reduced mobility of cervical spine, glottic and supraglottic airway obstruction, pharyngeal 
abscess/haematoma), increased risk of aspiration (full stomach, gastroesophageal reflux disease, hiatus hernia, intestinal obstruction, delayed gastric emptying due to opioid, pregnancy or alcohol administration).

\section{Study Procedure}

Pre-Operative Assessment was done 1 day prior to surgery. A detailed history and examination of the patients was done. Patients were prepared by overnight fasting. Tablet Alprazolam $0.25 \mathrm{mg}$ was given at bedtime and repeated 2 hours preoperatively. In the pre-operative suite, patients were given injection diclofenac sodium $75 \mathrm{mg}$ and glycopyrrolate $0.2 \mathrm{mg}$ intramuscular 45 minutes prior to induction. Intravenous line was secured by appropriate size Teflon venous catheter and injection ranitidine $50 \mathrm{mg}$, injection metoclopromide $10 \mathrm{mg}$ were given 40 minutes before surgery.

PLMA to be used for the procedure was subjected to all pre-use check-ups and availability of the correct size was ensured. On the operation table, infusion of ringer lactate was started and monitors were attached for continuous record of ECG, Blood Pressure (Systolic, Diastolic, Mean) and Oxygen saturation $\left(\mathrm{SpO}_{2}\right)$. B After preoxygenation for 3 minutes, induction of anesthesia was done with injection propofol $2 \mathrm{mg} / \mathrm{kg}$ followed by injection suxamethonium $1.5 \mathrm{mg} / \mathrm{kg}$ for muscle relaxation and was given Injection tramadol $0.4-0.5 \mathrm{mg} / \mathrm{kg}$ as analgesic. Then according to the groups the respective device was inserted.

Group I: PLMA (size 3 in females and size 4 in males) using standard introducer technique.

Group II: cuffed ETT (size 7-7.5 ID for females, size 8-8.5 ID for males).

PLMA cuff was thoroughly deflated with a syringe using cuff-deflating tool \& lubrication was applied to the posterior cuff surface. Following optimal placement in hypopharynx, the mask was inflated with $20-30 \mathrm{ml}$ of air to obtain a seal. Correct placement of both PMLA and ETT was ensured by auscultation, chest expansion, absence of leak on auscultation of epigastrium and neck, leak test by passage of gastric tube into stomach via drain tube. Insertion characteristics of PLMA or ETT and of NGT via PLMA or ETT like time taken for insertion and number of attempts taken were noted. The NGT was inserted 10 minutes after the placement of the device and connected to intermittent suction for the duration of surgical procedure in both the groups. Anesthesia was maintained with $33 \% \mathrm{O}_{2}, 66 \% \mathrm{~N}_{2} \mathrm{O}$ and $0.5 \%$ $1 \%$ Isoflurane and injection vecuronium 0.1 $\mathrm{mg} / \mathrm{kg}$. Ventilation was controlled mechanically using closed circuit with $\mathrm{CO}_{2}$ absorber. Abdominal cavity was insufflated with $\mathrm{CO}_{2}$ and intra-abdominal pressure maintained at $10-12 \mathrm{~mm}$ $\mathrm{Hg}$ with flow rate ranging from 1.8-2 1/min. Head up and lateral tilt was provided at the surgeon's request. Haemodynamic responses $\mathrm{SpO}_{2}$, Heart Rate (HR), blood pressures- Systolic, Diastolic \& Mean (SBP, DBP, MAP) were monitored at preinduction, after insertion of either device, after NGT insertion, before \&10 minutes after pneumoperitoneum and post-operatively.

Intra-operative complications like gastric distension, aspiration, presence or absence of any gastric contents through gastric tube and secretions were noted over PLMA. Secretions, if at all present over PLMA were removed and their $\mathrm{pH}$ was done. Peritoneal insufflation time and total anaesthetic time were also noted.

At the end of surgery patients were reversed using injection neostigmine $0.05 \mathrm{mg} / \mathrm{kg}$ andinjection glycopyrrolate $0.008 \mathrm{mg} / \mathrm{kg}$. Before extubation, stomach was again emptied, NTG was removed and thereafter device (PLMA or ETT) was removed when patient was able to open the mouth on command. Postoperative complications like cough, vomiting, laryngospasm and need for airway intervention during emergence from anesthesia were noted in all the patients.

\section{Statistical Analysis}

The data was analyzed with the help of computer software MS-excel and SPSS12.0 for windows. Outcomes were reported as percentages for qualitative variables and mean and standard deviation for quantitative variables. Unpaired " $t$ " 
test/Chi-square/Fisher's exact test were employed to evaluate statistical significance between the two groups. A p-value of $<0.05$ was considered as statistically significant.

\section{Observations and Results}

A total of 50 patients were randomized after checking inclusion and exclusion criteria. Both the two groups were comparable in age, sex and weight distribution as shown in Figure 1. Insertion timings showed a mean value of 16.24 and 26.68 seconds in PLMA and ETT groups respectively and this difference was statistically significant with $\mathrm{p}=0.0001$. Mean NGT insertion timings through PLMA and ETT groups were 14.16 and 26.6 seconds respectively which were also highly statistically significant.

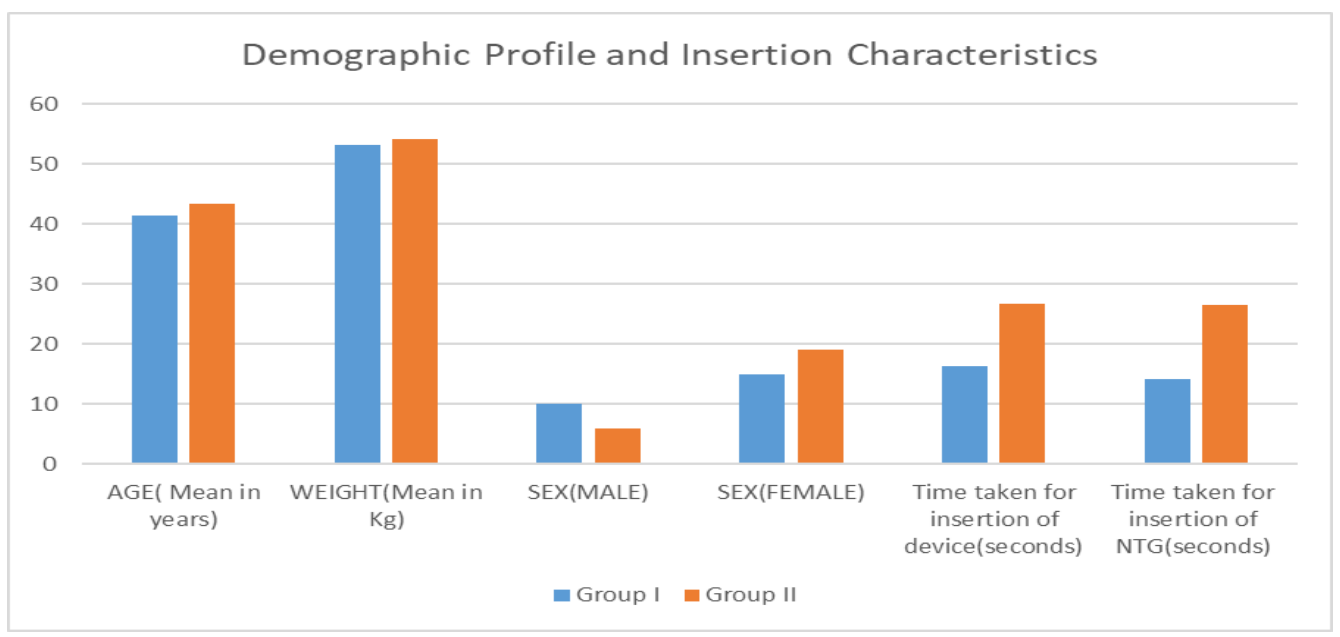

Figure 1: Demographic Profile and Insertion Characteristics

PLMA was successfully inserted in 1st attempt in $88 \%$ of cases and required 2 nd attempt in $12 \%$ of cases whereas ETT was inserted in 1st and 2nd attempts in $84 \%$ and $16 \%$ of cases respectively and was statistically insignificant with $\mathrm{p}=0.75$ (Table I). Insertion success rate for NGT placement in PLMA and ETT groups was comparable in both the groups i.e. $96 \%$ for 1 st attempt and $4 \%$ for 2nd attempt. No patient required 3rd attempt for any of the devices' placement.

Table I Insertion attempts 1, 2, 3, failed

\begin{tabular}{|l|c|c|}
\hline & $\begin{array}{c}\text { Group I } \\
\text { PLMA }\end{array}$ & $\begin{array}{c}\text { Group II } \\
\text { ETT }\end{array}$ \\
\hline PLMA $^{*}$ & $22,3,0,0$ & $21,4,0,0$ \\
\hline NGT & $24,1,0,0$ & $24,1,0,0$ \\
\hline
\end{tabular}

*fischer's exact test

\section{Haemodynamic Parameters}

The observations HR, SBP, DBP and MAP are shown in Figure 2. We observed that the values were comparable at all the intervals except for those after insertion. After insertion, H.R values were comparable with means of 16.24 and 26.68 beats/min. in groups I and II respectively with $\mathrm{p}=$ 0.89. But SBP, DBP and MAP showed statistically significant difference which was more in ETT group than PLMA group. Mean values for SBP were $122.68 \pm 12.9 \mathrm{mmHg}$ with $\mathrm{p}$ value of 0.0001 . Mean values for DBP were $78.56 \pm$ $9 \mathrm{mmHg}$ and $88.6 \pm 7.8 \mathrm{mmHg}$ with $\mathrm{p}$ value of 0.0001 . Mean values for MAP were $78.56 \pm$ $9 \mathrm{mmHg}$ and $88.6 \pm 7.8 \mathrm{mmHg}$ with $\mathrm{p}$ value of 0.0001 . 


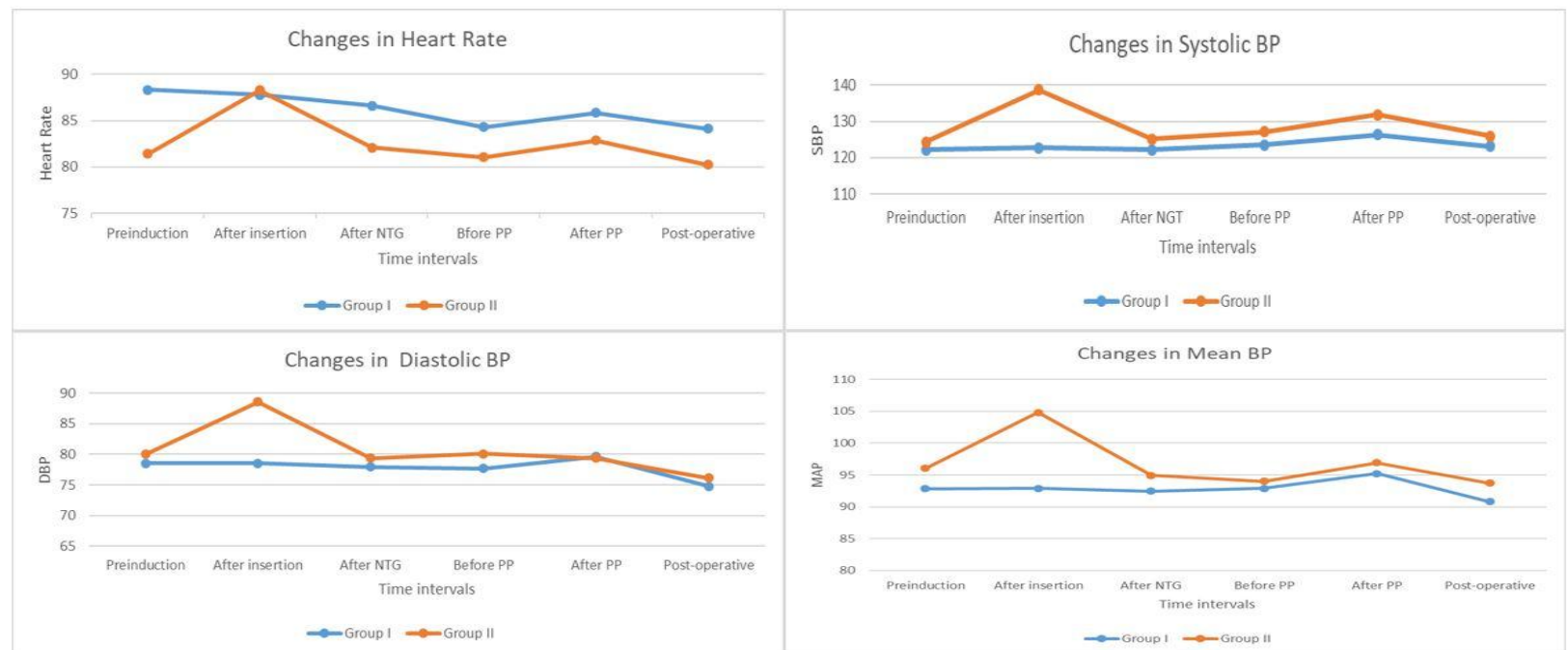

Figure 2: Haemodynamic Parameters- Heart rate,Systolic BP, Diastolic BP and Mean BP

Gastric distension was reported in 1 of our cases in PLMA group while secretions over PLMA were noticed in 2 of the patients and their $\mathrm{pH}$ as determined by litmus paper technique was > 6.There was no case of regurgitation or aspiration noted in any of the patients in each group. Overall incidence of complications was comparable in both the groups with $\mathrm{p}=0.11$ (Table III).

Table III Intra-operative Complications

\begin{tabular}{|l|c|c|}
\hline 1. Gastric distension & $\begin{array}{c}\text { PLMA } \\
1 / 25\end{array}$ & $\begin{array}{c}\text { ETT } \\
0 / 25\end{array}$ \\
\hline 2. Aspiration & Nil & Nil \\
\hline 3. Regurgitation & Nil & Nil \\
\hline
\end{tabular}

Fisher's Exact Test, $\mathrm{p}=0.11$

There was no statistically significant difference in mean values of peritoneal insufflation time being $77.36 \pm 16.88$ and $80.36 \pm 15.6$ seconds. in group I and II respectively ( $\mathrm{p}$ value $=0.51$ ). The total anesthetic time was also comparable in both the groups being $93.44 \pm 21 \mathrm{~min}$ and $98.12 \pm 18.86 \mathrm{~min}$ with $p$ value of 0.41 (Table II).

Table II Peritoneal Insufflation time and total anaesthetic time

\begin{tabular}{|l|c|c|c|}
\hline & Group I & Group II & p \\
\hline \begin{tabular}{l} 
Peritoneal $\begin{array}{l}\text { Insufflation Time } \\
\text { (minutes) }\end{array}$ \\
\hline $\begin{array}{l}\text { Total Anaesthetic } \\
\text { Time (minutes) }\end{array}$
\end{tabular} & $97.36 \pm 16.88$ & $80.36 \pm 15.61$ & 0.51 \\
\hline
\end{tabular}

*all values are expressed as mean and standard deviation Post-operative complications are shown in Table IV. Cough was reported in 2 patients with PLMA and 8 patients with ETT. No laryngospasm was reported in patients with PLMA while 1 case of laryngospasm was reported after ETT. Sore throat reported in 3 patients in PLMA group while in 6 patients in ETT group. One case of vomiting was reported after PLMA while none in ETT group. Overall incidence of respiratory events at extubation was comparable with $\mathrm{p}$ value of 0.47 .

Table-IV Postoperative complications

\begin{tabular}{|l|c|c|}
\hline 1. None & $\begin{array}{c}\text { Group I } \\
19 / 25\end{array}$ & $\begin{array}{c}\text { Group II } \\
10 / 25\end{array}$ \\
\hline 2. Cough & $2 / 25$ & $8 / 25$ \\
\hline 3. Laryngospasm & Nil & 1 \\
\hline 4. Bronchospasm & Nil & Nil \\
\hline 5. Positive Pressure Ventilation & Nil & Nil \\
\hline 6. Tracheal Intubation & Nil & Nil \\
\hline 7. Sore throat & $3 / 25$ & $6 / 25$ \\
\hline 8. Vomiting & $1 / 25$ & Nil \\
\hline Total & $\mathbf{6 / 2 5}$ & $\mathbf{1 5 / 2 5}$ \\
\hline
\end{tabular}

Chi square test $x^{2}=6.65$

\section{Discussion}

The present study was done to evaluate and compare the use of PLMA (Group I) in patients undergoing laparoscopic cholecystectomy under general anesthesia with controlled ventilation with ETT (Group II). We chose this procedure because increased intra-abdominal pressure from pneumoperitoneum requires the higher airway pressures for adequate pulmonary ventilation for which the PLMA was designed.

Our patients were comparable in age, weight and sex distribution data. We found that PLMA and ETT were successfully inserted in all the patients $\&$ there was no failed case of insertion in any of the two groups. Insertion time for PLMA was 
shorter as compared to ETT and NTG was inserted successfully in both the groups being quicker via the PLMA. This could be beneficial in patients with hypertension, ischemic heart disease etc. ${ }^{6}$ When we compare our results with literature, it was observed that our findings are consistent with those noted in most of the studies. ${ }^{6,7,8}$ In the study by Lim $\mathrm{Y}$ et $\mathrm{al}^{9}$, the maximum attempts required for insertion were 2 in number and there was no episode of failed ventilation as was found in our study. Malt by JR et $\mathrm{al}^{5}$ in their study found that 4 obese patients crossed over from PLMA to ETT in laparoscopic cholecystectomy and explained that these failures represent the presence of a learning curve on their part, rather than a problem with the device.

In haemodynamic parameters, we found that there was not much difference in the pulse rate at the respective intervals between both the groups as was shown by Shroff PP et al. ${ }^{6}$ However, in their study statistically significant difference was seen in pulse rate values before and after pneumoperitoneum being more in PLMA group which is in contrast to our study.

In our study, systolic, diastolic and mean blood pressures were comparable in both the groups at various intervals except for a statistically significant difference seen after insertion of both devices. It was found that SBP, DBP \& MAP values were much lower in PLMA group after insertion which was statistically significant. Our results are in accordance with Shroff PP et al ${ }^{6}$, SS Parikh et $\mathrm{al}^{8}$, Idrees Khan et $\mathrm{al}^{10}$. They stated that PLMA may be recommended for patients with cardiac and respiratory problems because of stable haemodynamics and quicker insertion and found it to be a safe airway management device for controlled ventilation during the laparoscopic procedures. The mechanism for haemodynamic changes associated with ETT/LMA insertion offered by most of the authors ultimately rests on the alteration of plasma catecholamine levels. ETT insertion leads to total afferent stimulation (pharyngeal as well as laryngeal), while LMA insertion causes only partial afferent stimulation (pharyngeal). As afferent fibres mediate the sympathetic stimuli, their stimulation leads to the release of catecholamines in the blood which are ultimately responsible for pressor responses.

In intra-operative complications we found $1(4 \%)$ case of minimal gastric distention visible on the laparoscopic television monitor while using PLMA. This however did not disturb the surgeon and was not quantitatively measured and the surgery went on successfully. No case of gastric distention was reported in ETT group. Shroff et $\mathrm{al}^{6}$ noted 3\% gastric distention in PLMA group while none in ETT group and was in accordance with our study. Malt by JR et $\mathrm{al}^{11}$ concluded the same however they cautioned that their results should not be interpreted so as to mean that gastric distention does not occur in laparoscopic surgery but rather that it occurs with equal frequency and to the same degree with both the LMA and ETT. Brimacombe $\mathrm{J}^{12}$ et al also concluded that gastric insufflation is possible if PLMA is malpositioned. However, Chakraborty et $\mathrm{al}^{13}$ on comparing gastric distention during laparoscopic cholecystectomy found the incidence of gastric distention to be lower in PLMA. This is not in accordance with the present study. They postulated that in PLMA series, mask ventilation was not required as the placement of PLMA was done soon after induction. Besides requirement of anaesthetic depth is less during PLMA insertion and NGT insertion is easier through it than when ETT in situ.

In the present study, we noticed no case of regurgitation of gastric contents through the drain tube in case of PLMA as we had ensured previously that all our patients received appropriate premedication to minimize gastric volume and acidity and NGT was inserted in all our patients and intermittent suctioning was applied. There was no case of regurgitation of gastric contents into the bowl of PLMA which was consistent with other studies. ${ }^{6,8,14}$ The studies by Malt by JR et $\mathrm{al}^{15}$, Sharma Bimla et $\mathrm{al}^{16}$ and Sharma Bimla et $\mathrm{al}^{7}$ reported $3 \%, 1 \%$ and $2.5 \%$ cases of regurgitation into the drain tube 
respectively and concluded that PLMA drainage tube prevents passively regurgitated liquid from contaminating the airway which is comparable with the present study.

In our study there was no case of pulmonary aspiration in PLMA group although it was too small to determine the danger of an unprotected airway \& risk of aspiration pneumonitis which was similar to other studies. ${ }^{7,13,15}$

In our study, arterial oxygen saturation remained maintained between 98-100\% throughout the procedure in both the groups indicating adequate ventilation and absence of hypoxia. This was comparable to other studies. ${ }^{6,15,16}$ However, Sharma Bimla et $\mathrm{al}^{7}$ reported transient suboptimal oxygenation (SpO2- 94\%) in one patient undergoing extraperitoneal inguinal hernia repair and was found to be due to extensive subcutaneous emphysema which had developed due to trocar misplacement in the post insufflation period.

Peritoneal insufflation time and total anaesthetic time were comparable in both of our groups. Brimacombe $\mathrm{J}^{17}$ in his study quoted duration of peritoneal insufflation time $<15$ min with use of CLMA, however, later studies ${ }^{5,15}$ did not limit the duration of peritoneal insufflation and used PLMA for as long as 300 minutes without any problem. The reason given by them was that inadequate ventilation or gastric distention should be evident within $15 \mathrm{~min}$ of starting the laparoscopic procedure, if it does not occur within $15 \mathrm{~min}$, it should not occur later provided that anaesthetic depth and muscular relaxation are adequate and PLMA is not dislodged. Peritoneal insufflation and total anaesthetic times were also comparable between PLMA and ETT in the above studies.

Postoperative complications such as cough, sore throat were more common in the ETT group indicating smoother emergence with PLMA group in our study. Overall respiratory events such as laryngospasm, bronchospasm, positive pressure ventilation, tracheal intubation were not seen in PLMA group but laryngospasm was reported in one of the patients in ETT group. This was in accordance with other studies. ${ }^{6,15}$ However, in studies by Patodi V et $\mathrm{al}^{18}$ and $\mathrm{N}$ Saraswat et $\mathrm{al}^{19}$ frequency of complications during emergence were significantly more in ETT group. The lower incidence of cough and sore throat with PLMA is explained by the fact that it causes less mucosal pressure and does not hinder the pharyngeal perfusion pressure.

Vomiting occurred in one of our patients after PLMA removal. No particular reason for vomiting could be ascertained and it settled of its own immediately. However, Hohlrider $\mathrm{M}$ et $\mathrm{al}^{20}$ showed that PLMA reduced the absolute risk of post-operative nausea and vomiting by $40 \%$ also because of the reason that cuff of PLMA is less stimulating to pharyngeal mucosa as compared to ETT cuff causing lesser airway morbidity in PLMA group.

From the discussion above, it appears that the PLMA insertion is quicker and it aids easy and rapid insertion of NGT. Complications are minimal and haemodynamic responses are definitely attenuated with PLMA as compared to ETT insertion.

\section{Conclusion}

It can be concluded that Proseal Laryngeal Mask ay (PLMA) is a safe and equally effective alternative to an Endotracheal tube (ETT) for airway management of elective fasting patients undergoing laparoscopic cholecystectomy as judged by stable haemodynamics, good oxygenation and adequate ventilation. However, we recommend further studies with larger sample size to make significant differences between the two techniques so that the results could be better appreciated.

\section{Conflicts of Interest}

There are no conflicts of interest

\section{References}

1. Brimacombe $\mathrm{J}$ : The advantages of LMA over tracheal tube or facemask a 
metaanalysis. Canadian Journal of Anesthesia1995;42:1017-1023.

2. Alexander CA, Leach AB: Incidence of sore throats with laryngeal mask. Anesthesia1989; 44:791.

3. Stone JM, Karaliedde LD, Carter ML, Cumberland N. Bacteremia and insertion of laryngeal mask airways. Anesthesia 1992;42:77.

4. Evans NR, Gardener SV, James MFM: Proseal Laryngeal Mask protects against aspiration of fluid in the pharynx. British Journal of Anesthesia 2002;88(4):584-587.

5. Maltby JR, Beriault MT, Watson NC, Liepert DJ, Fick GH:LMA Proseal is an effective alternative to tracheal intubation for laparoscopic cholecystectomy. Canadian Journal of Anesthesia 2002:49(8):857-862.

6. Shroff PP, Kamath S: Randomized comparative study between the Proseal Laryngeal Mask and the Endotracheal tube for laparoscopic surgery. Internet Journal of anesthesiology ISSN: 2006;11(1).

7. Sharma B, Sood J, Sahai C, Kumra VP: Efficacy and safety performance of Proseal Laryngeal Mask Airway in Laparoscopic surgery: Experience of 1000 cases. Indian Journal Of Anesthesia 2008:52 (3):288296.

8. Parekh SS, Parekh Shivam Bipin, Chaula Doshi, Versha Vyas: Proseal Laryngeal Mask airway versus cuffed endotracheal tube for laparoscopic surgical procedures under general anesthesia: A random comparative study. Anesth Essays Res 2017 Oct-Dec11(4):958-963.

9. Lim Y, Goel S, Btomacombe JR: The Proseal Laryngeal Mask Airway is an effective alternative to laryngoscopic guided tracheal intubation for gynaecological laparoscopy. Anesth Intensive Care 2007 Feb;35(1):52-56.

10. Idrees A, Khan FA: A comparative study of positive pressure ventilation via laryngeal mask airway and endotracheal tube. J Pak Med Assoc 2000; 50:333-338.

11. Maltby JR, Beriault MT, Watson NC, Liepert DJ, Fick GH: Gastric distension and ventilation during laparoscopic cholecystectomy: LMA classic versus tracheal intubation.

12. Chakraborty Arpan, Kumar G Parveen, Bhattacharya Prithwis: Gastric distension during laparoscopic cholecystectomy: Comparison between ETT and PLMA. Internet Journal of Anesthesiology ISSN :1092-406X.

13. Brimacombe J, Keller C, Berry A: Gastric insufflation with the Proseal Laryngeal Mask. Anesthesia Analgesia 2001;92(6):1614.

14. Roth H, Genzwuerker HV, Rothhas A, Finteis T, Schmeck J:Proseal Laryngeal Mask airway and the laryngeal tube suction for ventilation in gynaecological patients undergoing laparoscopic syrgery. Eur J Anesthesial 2005 Feb; 22(2):117122.

15. Maltby JR, Beriault MT, Watson NC, Liepert DJ, Fick GH: LMA Classic and LMA Proseal are effective alternatives to endotracheal intubation for gynaecologic laparoscopy. Canadian Journal OfAnesthesia2003;50(1):71-77.

16. Sharma B, Sahai C, Bhattacharya A, Kumra VP, Sood J: Proseal Laryngeal Mask Airway: A study of 100 consecutive cases of laparoscopic surgery. Indian Journal of Anesthesia2003;47:467-472.

17. Brimacombe J: Analysis of 1500 laryngeal mask uses by one anaesthetist in adults undergoing routine anesthesia. Anesthesia1996;51:76-80.

18. Patodi V, Singh M, Sethi SK, Deepal V N, Jain N, Kumar V: A comparative study between Proseal Laryngeal Mask Airway and Endotracheal Tube for ease of insertion and haemodynamic changes in patients undergoing laparoscopic 
cholecystectomy under general anesthesia.

IJRMS vol4, No.12 (2016).

19. Saraswat N, Kumar A, Mishra A, Gupta A, Saurabh G, Srivastava U: The comparison of Proseal Laryngeal Mask Airway and Endotracheal Tube in patients undergoing laparoscopic surgeries under general anesthesia. Indian J Anaesth 2011; 55:129134.

20. Hohlrieder M, Brimacombe J, Von Goedecke A, Keller C: Postoperative nausea, vomiting, airway morbidity and analgesic requirements are lower for the Proseal laryngeal mask airway than the tracheal tube in females undergoing breast and gynaecological surgery. British Journal of Anesthesia 2007, Oct;99 (4):576-580. 